\title{
New standards for intracranial atherosclerotic disease treatment
}

\author{
Thanh N. Nguyen ${ }^{1 *}$, Marc A. Lazzaro ${ }^{2}$ and Adnan I. Qureshi ${ }^{3}$ \\ 1 Departments of Neurology, Neurosurgery, and Radiology, Boston University School of Medicine, Boston, MA, USA \\ 2 Department of Neurology, Medical College of Wisconsin, Milwaukee, WI, USA \\ ${ }^{3}$ Zeenat Qureshi Stroke Research Center, University of Minnesota, Saint Paul, MN, USA \\ ${ }^{*}$ Correspondence: thanh.nguyen@bmc.org
}

The stenting versus aggressive medical therapy for intracranial artery stenosis (SAMMPRIS) trial compared aggressive medical therapy to aggressive medical therapy and percutaneous angioplasty and stenting (PTAS) in patients with symptomatic intracranial atherosclerotic disease (ICAD; Chimowitz et al., 2011). The trial was halted when a higher 30 -day rate of stroke and death was present in the PTAS compared to the aggressive medical therapy group ( 14.7 vs. $5.8 \%, p=0.002$ ).

SAMMPRIS highlights the evolving definition and improving efficacy of aggressive medical therapy including aspirin and clopidogrel, statin, and antihypertensive treatments. SAMMPRIS sets the new standard for periprocedural stroke and death rates which neurointerventionalists and devices must achieve to demonstrate superiority of PTAS to aggressive medical therapy. The data from SAMMPRIS may allow a better understanding of underlying mechanism for adverse events such as intracranial hemorrhages related to PTAS and result in new strategies for preventing such events.
The results should not undermine the high risk of recurrent stroke in patients with symptomatic ICAD despite aggressive medical treatment. Several subgroups of ICAD patients at high risk of ischemic events have been identified such as those with high grade stenosis, posterior circulation involvement, precipitation of ischemic symptoms by systemic blood pressure changes, and recurrent ischemic events (Thijs and Albers, 2000). Until the next stent emerges, intracranial angioplasty (Marks et al., 2005; Nguyen et al., 2011) may be an alternative for this subgroup and should be evaluated against aggressive medical therapy in a randomized trial.

\section{REFERENCES}

Chimowitz, M. I., Lynn, M. J., Derdeyn, C. P., Turan, T. N., Fiorella, D., Lane, B. F., Janis, S., Lutsep, H. L., Barnwell, S. L., Waters, M. F., Hoh, B. L., Hourihane, J. M., Levy, E. I., Alexandrov, A. V., Harrigan, M. R., Chiu, D., Klucznik, R. P., Clark, J. M., McDougall, C. G., Johnson, M. D., Pride, L., Torbey, M. T., Zaidat, O. O., Rumboldt, Z., Cloft, H. J., and SAMMPRIS Trial Investigators. (2011). Stenting versus aggressive medical therapy for intracranial artery stenosis. $N$. Engl. J. Med. 365, 993-1003.

Marks, M. P., Marcellus, M. L., Do, H. M., SchraedleyDesmond, P. K., Steinberg, G. K., Tong, D. C., and Albers, G. W. (2005). Intracranial angioplasty without stenting for symptomatic atherosclerotic stenosis: long-term follow-up. Am. J. Neuroradiol. 26, 525-530. Nguyen, T., Zaidat, O. O., Gupta, R., Nogueira, R. G., Tariq, N., Kalia, J. S., Norbash, A. M., and Qureshi, A. I. (2011). Balloon angioplasty for intracranial atherosclerotic disease. Stroke 42, 107-111.

Thijs, V. N., and Albers, G. W. (2000). Symptomatic intracranial atherosclerosis: outcome of patients who fail antithrombotic therapy. Neurology 55, 490-498.

Received: 01 November 2011; accepted: 17 November 2011; published online: 20 December 2011.

Citation: Nguyen TN, Lazzaro MA and Qureshi AI (2011) New standards for intracranial atherosclerotic disease treatment. Front. Neur. 2:77. doi: 10.3389/fneur.2011.00077

This article was submitted to Frontiers in Endovascular and Interventional Neurology, a specialty of Frontiers in Neurology.

Copyright $\odot 2011$ Nguyen, Lazzaro and Qureshi. This is an open-access article distributed under the terms of the Creative Commons Attribution Non Commercial License, which permits non-commercial use, distribution, and reproduction in other forums, provided the original authors and source are credited. 